\title{
In vivo quantification of formulated and chemically modified small interfering RNA by heating-in-Triton quantitative reverse transcription polymerase chain reaction (HIT qRT-PCR)
}

Yosef Landesman ${ }^{*}$, Nenad Svrzikapa, Armand Cognetta III, Xuemei Zhang, Brian R Bettencourt, Satya Kuchimanchi, Keri Dufault, Sarfraz Shaikh, Maple Gioia, Akin Akinc, Renta Hutabarat, Rachel Meyers

\begin{abstract}
Background: While increasing numbers of small interfering RNA (siRNA) therapeutics enter into clinical trials, the quantification of siRNA from clinical samples for pharmacokinetic studies remains a challenge. This challenge is even more acute for the quantification of chemically modified and formulated siRNAs such as those typically required for systemic delivery.

Results: Here, we describe a novel method, heating-in-Triton quantitative reverse transcription PCR (HIT qRT-PCR) that improves upon the stem-loop RT-PCR technique for the detection of formulated and chemically modified siRNAs from plasma and tissue. The broad dynamic range of this assay spans five orders of magnitude and can detect as little as $70 \mathrm{pg}$ duplex in $1 \mathrm{~g}$ of liver or in $1 \mathrm{ml}$ of plasma. We have used this assay to quantify intravenously administrated siRNA in rodents and have reliably correlated target reduction with tissue drug concentrations. We were able to detect siRNA in rat liver for at least 10 days post injection and determined that for a modified factor VII (FVII) siRNA, on average, approximately 500 siRNA molecules per cell are required to achieve a $50 \%$ target reduction.

Conclusions: HIT qRT-PCR is a novel approach that simplifies the in vivo quantification of siRNA and provides a highly sensitive and reproducible tool to measure the silencing efficiency of chemically modified and formulated siRNAs.
\end{abstract}

\section{Background}

Several small interfering RNA (siRNA)-based therapeutics are currently in various phases of preclinical and clinical development [1-3]. There is an unmet need to develop sensitive methods to detect and quantify siRNAs in cells and tissues. Therapeutic siRNAs for systemic delivery are typically chemically modified and formulated. Chemical modifications of the sugar-phosphate backbone stabilise siRNA duplexes by enhancing their nuclease resistance and increasing their specificity by reducing offtarget effects [4]. Of all delivery systems described, the

\footnotetext{
* Correspondence: ylandesman@alnylam.com

Alnylam Pharmaceuticals, Cambridge, MA, USA
}

formulation of siRNAs within cationic lipid nanoparticles (LNPs) is the most validated method for delivery to liver and possibly to other organs [5]. While chemical modifications contribute to increased siRNA stabilisation and specificity, they can significantly increase duplex melting temperature. Moreover, although formulations enhance siRNA tissue delivery and cellular uptake, they can inhibit siRNA release and detection. Currently used siRNA quantification methods include visualisation of radiolabelled siRNAs, hybridisation-based assays with labelled probes using enzyme-linked immunosorbent assays (ELISAs; specifically, hybridisation ELISA), methods based on high performance liquid chromatography (HPLC), 
capillary gel electrophoresis (CGE) and liquid chromatography mass spectrometry (LC-MS) alone or in combination with hybridisation-based assays (reviewed by Tremblay and Oldfield [6]). The most sensitive of these bioanalytical methods is the hybridisation ELISA with lower limit of quantification (LLOQ) of approximately 1 $\mathrm{ng} / \mathrm{ml}$ of a 20-mer oligonucleotide in plasma and approximately $1 \mathrm{ng} / \mathrm{g}$ in liver [7]. However, these assays are laborious and have limited sensitivity. A more sensitive assay that is simple and fast to perform and that allows the quantification of therapeutic siRNAs from tissue and plasma is greatly needed.

Recently, Chen et al. developed a stem-loop quantitative reverse transcription PCR (qRT-PCR) method for the quantification of microRNAs (miRs) from tissue culture cells [8]. This assay is particularly appealing because of its high sensitivity, selectivity, and broad dynamic range for the detection of short RNA single strands characteristic of mature miRs. However, when applied to the detection of siRNA duplexes in liver, the stem-loop RT-PCR assay demonstrated a poor dynamic range and suboptimal amplification, suggesting inefficiencies in the RT and PCR steps $[9,10]$. In addition, amplification efficiency was lower for chemically modified versus unmodified siRNAs [9]. Such differences may result from the double-stranded nature of siRNAs, their chemical modifications and formulations.

Here, we describe the heating-in-Triton (HIT) method that, when used in combination with the stem-loop qRT-PCR technique, allows robust siRNA quantification from cell lines, tissues and plasma. Using this assay we measured unmodified and chemically modified siRNAs, either as unformulated (naked) siRNAs, or as formulated duplexes within LNPs $[11,12]$. Importantly, this assay is strand specific and thus requires complete denaturation of the sense and antisense strands. The assay is highly specific and sensitive, with a broad dynamic range of approximately five orders of magnitude that allows the detection of as little as $70 \mathrm{pg}$ siRNA in $1 \mathrm{~g}$ of tissue or $1 \mathrm{ml}$ of plasma. With simple and rapid sample processing, high reproducibility and applicability independent of the chemical modification or delivery strategy employed, this assay is robust and easily adapted for high throughput bioanalytical quantification of siRNA in vivo.

\section{Results}

siRNA quantification requires duplex liberation from the formulation followed by strand separation

We evaluated the amplification of two naked siRNA duplexes and their antisense single strands by qRT-PCR using the stem-loop method [8]. Both siRNAs target rat factor VII (FVII) and have identical sequences, but differ in backbone chemical modifications that increase the melting temperature of the modified duplex: AD1661 (modified duplex) is identical to AD1596 (duplex) except that it contains 2 -fluoro-chemically modified nucleotides (Table 1). First, 10-fold serial dilutions (in water) of the two duplexes and their corresponding antisense strands were assayed in the qRT-PCR assay at room temperature $\left(25^{\circ} \mathrm{C}\right)$ (Figure 1a). Comparison of the four amplification curves confirmed that modified and unmodified antisense strands were detected with equal efficiency, while less antisense strands were detected from the duplex under these same conditions. The underestimation of duplex concentrations ranged between 6 -fold to 256 -fold, and correlated with duplex concentration: at the highest concentrations, the average signal difference between duplex and single strand was 8 average cycle threshold units ( $\mathrm{AvCt})$, and at the lowest concentrations the difference was $2.5 \mathrm{Av} \mathrm{Ct}$ (Figure 1a). The difference in the detection of free antisense stands and the same antisense strands in the context of a duplex could be due to the inefficiency of RT in the presence of an equimolar amount of annealed sense strand found in the duplex samples. Comparison of the amplification curves of the modified and unmodified duplexes shows that the antisense strand from the unmodified duplex was slightly more efficiently detected than the antisense strand from the modified duplex. The decrease in RT efficacy for the chemically modified duplex is likely explained by its higher melting temperature (Table 1). Therefore, strand separation prior to RT may improve amplification curves for the detection of antisense strands from the siRNA duplex.

To test the effect of strand separation on siRNA detection by qRT-PCR, two siRNA duplexes and their matching antisense strands were heated for 10 minutes at $95^{\circ} \mathrm{C}$ and directly added into the RT reaction. Under these conditions, similar amplification curves were obtained for duplexes and single strands, particularly at concentrations equal or below $1.7 \mathrm{nmol}$ siRNA per RT reaction (3.35 fmol per PCR reaction, see the $-2.5 \mathrm{log}$ siRNA point in Figure 1b), suggesting that duplex siRNAs can be accurately measured when the RT is performed on melted duplexes (Figure 1b).

In vivo delivery typically requires siRNAs formulation in LNPs prior to intravenous injection $[11,13]$. LNPs impose an additional barrier to quantification as the siRNA must be efficiently liberated from the particles before quantification. To test our ability to quantify LNP-formulated siRNAs, serial dilutions of the modified siRNA encapsulated in an LNP containing the novel lipid KC2 [5] (KC2 mod Dup), were compared to the modified unformulated siRNA (mod Dup) and the modified antisense strand $(\bmod$ AS) (Figure 1c). As we had seen previously, unformulated duplex and single strands, heated at $95^{\circ} \mathrm{C}$, showed similar amplification curves over 
Table 1 Small interfering RNA (siRNA) duplexes

\begin{tabular}{|c|c|c|c|c|}
\hline Text name & Alnylam name & Sequence & Melting temperature & Target \\
\hline Duplex & AD1596 & & & \\
\hline Sense & Sense: A4639 & GGAUCAUCUCAAGUCUUACdTdT & $70.1^{\circ} \mathrm{C}$ & $\mathrm{FVII}$ \\
\hline AS & AS: A4640 & GUAAGACUUGAGAUGAUCCdTdT & & Murine \\
\hline Mod duplex & AD1661 & & & \\
\hline Mod sense & Sense: A4723 & GGAUfCfAUfCfUfCfAAGUfCfUfUfACfdTsdT & $83.4^{\circ} \mathrm{C}$ & $\mathrm{FVII}$ \\
\hline Mod AS & AS: A4724 & GUfAAGACfUfUfGAGAUfGAUfCfCfdTsdT & & Murine \\
\hline AD6490 & AD6490 & & & \\
\hline A5296 & Sense: A5296 & GGAAUCuuAuAuuuGAUCcAsA & $70.1^{\circ} \mathrm{C}$ & APOB \\
\hline A5475 & AS: A5475 & uuGGAUcAAAuAuAAGAuUCcscsU & & Human \\
\hline AD1955 & AD1955 & & & \\
\hline A3374 & Sense: A3372 & cuuAcGcuGAGuAcuucGAdTsdT & $78.0^{\circ} \mathrm{C}$ & Luciferase \\
\hline A5475 & AS: A3374 & UCGAAGuACUcAGCGuAAGdTsdT & & Firefly \\
\hline
\end{tabular}

The sequences of the two duplexes AD1596 and AD1661 are identical, except that AD1661 contains chemical modifications. AD6490 and AD1955 are unrelated duplexes. The gene target of each siRNA is indicated. Chemical modifications are indicated as follows: 2'-O-Me-modified nucleotides are shown by lower case letters, 2 '-fluoro-modified nucleotides are shown by ' $f$ ' following the modified nucleotide and phosphorothioate linkages are shown by ' $s$ '. All sequences are written in the 5'-3' direction.

Alnylam name refers to Alnylam Pharmaceuticals in-house name.

$\mathrm{APOB}=$ apolipoprotein $\mathrm{B} ; \mathrm{AS}=$ antisense; FVII = factor VII; mod = modified.

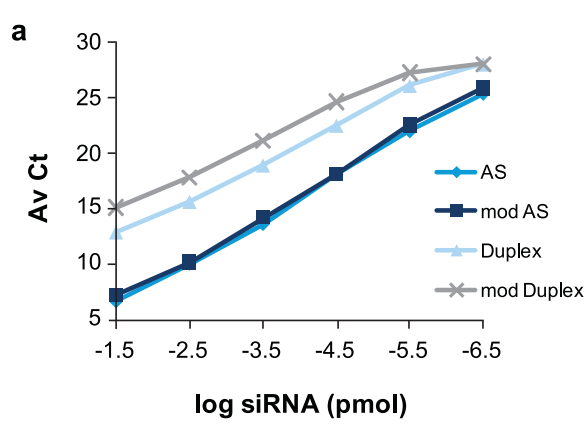

C

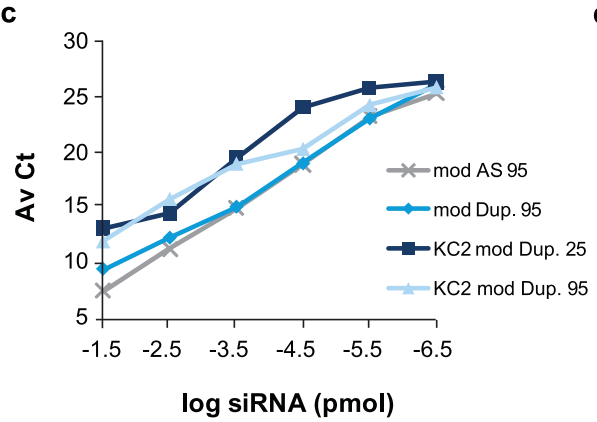

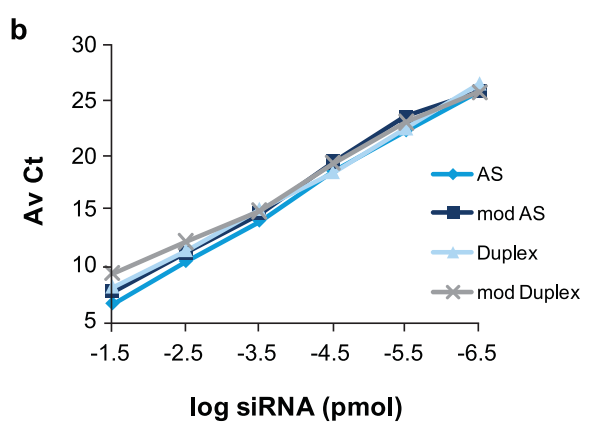

d

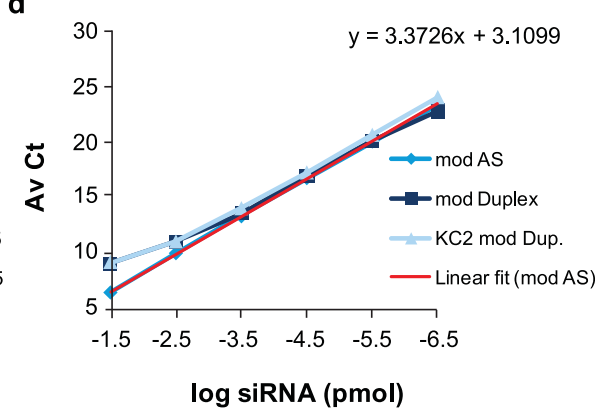

Figure 1 Efficient small interfering RNA (siRNA) quantification requires release from the formulation and strand separation. Amplification curves of unmodified (antisense (AS)), modified AS (mod AS), duplex (Duplex), modified duplex (mod Duplex), and lipid nanoparticle (LNP)-KC2-formulated modified duplex (KC2 mod Dup) siRNAs. siRNAs were diluted as indicated either in water or in $0.25 \%$ Triton. Then were treated as indicated either at room temperature $\left(25^{\circ} \mathrm{C}\right)$ or heated to $95^{\circ} \mathrm{C}$ for $10 \mathrm{~min}$ and added directly into reverse transcription reactions: (a) water; $25^{\circ} \mathrm{C}$, (b) water, $95^{\circ} \mathrm{C}$, (c) water, $95^{\circ} \mathrm{C}$ for mod $\mathrm{AS}$, mod Dup and for $\mathrm{KC}$-mod Dup, both in $25^{\circ} \mathrm{C}$ and $95^{\circ} \mathrm{C}$, and (d) $0.25 \%$ Triton-phosphate-buffered saline (PBS); $95^{\circ} \mathrm{C}$. The linear regression of the amplification curve for chemically modified AS siRNA is shown (inear fit $(\bmod A S))$. The average cycle threshold $(A v C t)$ values $(n=3)$ indicate signals in single PCR reactions containing siRNA equivalent concentrations ranging between $3.35 \times 10^{-2}$ to $3.35 \times 10^{-7} \mathrm{pmol}$. 
at least four orders of magnitude, while formulated duplexes were amplified less efficiently. Therefore, we had to develop a method to disrupt LNP to liberate siRNAs for accurate quantification.

To release the siRNA from the LNP-KC2 formulation, we tested various detergents (data not shown) and ultimately selected $0.25 \%$ Triton $\mathrm{X}-100$ for addition to the formulated siRNA prior to heating at $95^{\circ} \mathrm{C}$. Under these conditions, nearly identical amplification curves were obtained for the modified antisense strand, modified duplex and LNP-KC2-formulated modified duplex (Figure 1d). A linear regression fit to the three amplification curves over five orders of magnitude showed an average slope of 3.2 , which indicated nearly $100 \%$ efficient amplification under these modified conditions (Figure 1d).

In order to confirm that the direct addition of the siRNA heated to $95^{\circ} \mathrm{C}$ in $0.25 \%$ Triton did not compromise reverse transcriptase activity, amplification curves of serially diluted antisense strands were evaluated with and without heating in triton. Similar amplification curves for the antisense strand under these two conditions confirmed that no enzyme inhibition had occurred (Figure 2). These results confirm that efficient amplification of antisense strands from LNP-formulated, chemically modified siRNA duplexes can be achieved under these conditions.

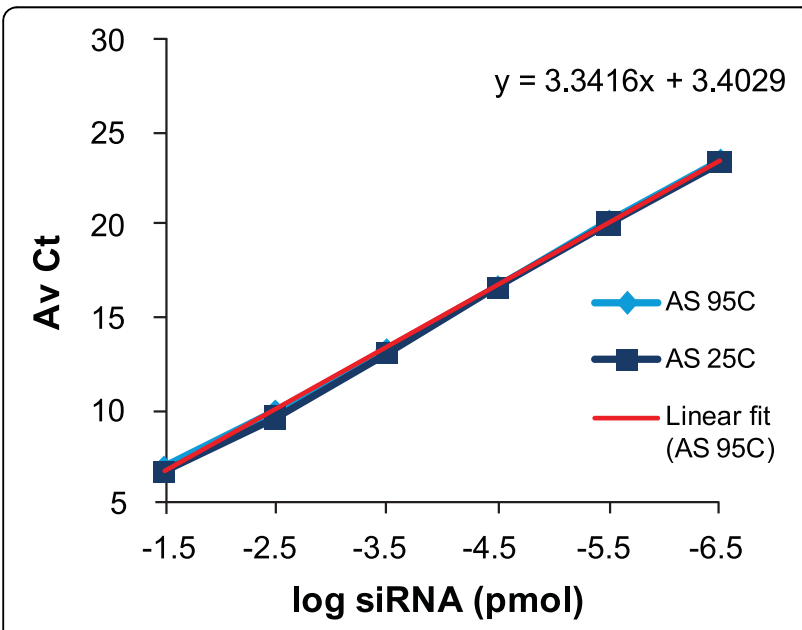

Figure 2 Amplification curves of modified antisense (AS) strands. AS strands were diluted in $0.25 \%$ Triton-phosphatebuffered saline (PBS), then were kept as indicated either at room temperature $\left(25^{\circ} \mathrm{C}\right.$ : AS $\left.25 \mathrm{C}\right)$ or heated to $95^{\circ} \mathrm{C}$ for $10 \mathrm{~min}$ and added directly into reverse transcription reactions (AS 95C). The linear regression of the amplification curve for chemically modified AS at $95^{\circ} \mathrm{C}$ is shown (linear fit (AS 95C)). The average cycle threshold (AvCt) values indicate signals in single $P C R$ reactions containing small interfering RNA (siRNA) equivalent concentrations ranging between $3.35 \times 10^{-2}$ to $3.35 \times 10^{-7} \mathrm{pmol}$. Each point is an average $\mathrm{n}=3$.

\section{High temperature is required to avoid reannealing}

The melting temperature ( $\mathrm{Tm}$ ) of the chemically modified duplex AD1661 was $83.4^{\circ} \mathrm{C}$ (Table 1). Based on this high $\mathrm{Tm}$, it is expected that reannealing of melted duplex will occur rapidly upon cooling, thus explaining the reduced dynamic range of the assay (Figure $1 b-d$ ). To confirm this interpretation, modified antisense strand, modified duplex, and the LNP-KC2-formulated modified duplex were heated for 10 minutes at $95^{\circ} \mathrm{C}$ and were assayed either directly, or allowed to cool to $85^{\circ} \mathrm{C}, 75^{\circ} \mathrm{C}$ or $25^{\circ} \mathrm{C}$ for 10 minutes prior to $\mathrm{RT}$ (Figure 3). When assayed directly at $95^{\circ} \mathrm{C}$, the amplification curves of all compounds were almost identical and linear over approximately 5 logs, with a slope of 3.3, which is characteristic of $100 \%$ efficiency (Figure 3a). However, careful analysis of the $\mathrm{Ct}$ values from inputs of $>3.4 \mathrm{E}^{-03} \mathrm{pmol}\left(>-2.5 \log\right.$ siRNA) at $95^{\circ} \mathrm{C}$, revealed an average of 1.4 Ct difference between modified antisense strand and the naked and formulated modified duplexes (Figures 1d and 3a). This difference can be explained by amplification inefficiencies observed when measuring highly concentrated duplexes that will more quickly anneal. The siRNA samples that were cooled down to $85^{\circ} \mathrm{C}$ were also efficiently amplified along most of the serial dilutions, except for the most concentrated duplex inputs that showed decreased amplification efficiencies of approximately $2 \mathrm{Av} \mathrm{Ct}$ units between the antisense strand and the tested duplexes (Figure $3 \mathrm{~b}$ ). Incubation at $75^{\circ} \mathrm{C}$ (Figure $3 \mathrm{c}$ ) or $25^{\circ} \mathrm{C}$ (Figure $3 \mathrm{~d}$ ) resulted in more significant reductions in amplification efficiency for the duplexes at the highest concentrations tested, confirming that reannealing is both temperature and concentration dependent. These data show that complete and continued denaturation of the duplex at high concentrations is essential for optimal quantification.

\section{Quantification of modified and formulated siRNA from plasma and liver tissue}

Having defined the conditions for efficient amplification of encapsulated chemically modified duplex siRNA in buffer, we next evaluated these conditions for siRNA in plasma and liver tissue. To do so, serial dilutions of LNP-KC2-formulated modified duplex, modified unformulated duplex, and modified antisense strand control were spiked into either naïve rat plasma (diluted 1:10 in $0.25 \%$ Triton heated to $95^{\circ} \mathrm{C}$ ) or liver lysate (diluted to $100 \mathrm{mg} / \mathrm{ml}$ tissue in $0.25 \%$ Triton heated to $95^{\circ} \mathrm{C}$ ). Spiked samples were centrifuged to remove debris and then reheated for 10 minutes at $95^{\circ} \mathrm{C}$ before direct addition into the qRT-PCR reaction. Nearly identical amplification curves were observed when comparing antisense strand alone with modified duplex and LNP-formulated modified duplex assayed in plasma (Figure 4a). Similarly, nearly indistinguishable amplification curves were 


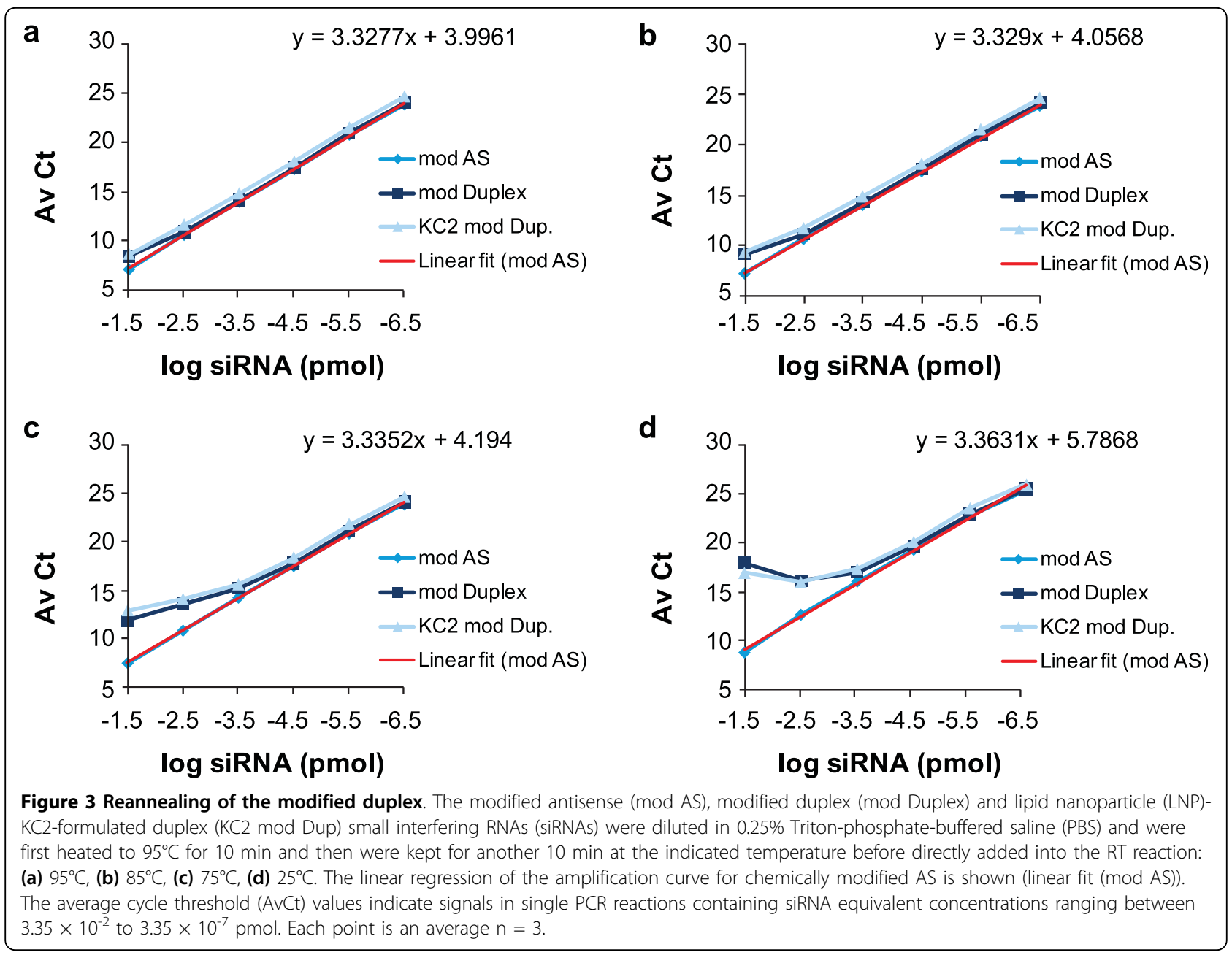

observed when these same siRNAs were assayed in liver tissue (Figure 4b). The assays were linear over four orders of magnitude and the amplification curves had slopes of approximately 3.2, demonstrating efficient amplification. Given the final plasma and liver tissue concentration in those standard curves, we concluded that the dynamic ranges of the two assays were $0.7 \mu \mathrm{g}$ to $70 \mathrm{pg}$ siRNA per $1 \mathrm{ml}$ of plasma and $0.7 \mu \mathrm{g}$ to $70 \mathrm{pg}$ of siRNA per $1 \mathrm{~g}$ of liver tissue (Figure 4).

To confirm that our method could be used for the quantification of siRNAs containing chemically modified bases other than 2'-fluoro and formulations other than LNP-KC2, we tested two additional chemically modified and formulated siRNAs in plasma. AD1955 is a 2'-OMe-modified siRNA formulated in LNP-KC2, while AD6490 is a 2'-O-Me-modified siRNA (Table 1), encapsulated in a distinct LNP formulation containing the lipid C12-200 (LNP-C12-200) [14]. Chemically modified antisense strands, duplexes and formulated duplexes were serially diluted in rat plasma and processed as described above. Similar amplification curves of the antisense strands, duplexes and formulated duplexes demonstrated a linear detection between $0.7 \mu \mathrm{g}$ to $70 \mathrm{pg}$ duplex/ml of plasma for both siRNAs (Figure 5). To further confirm the universal utility of this detection method, two additional siRNA spiking experiments were performed in rat liver lysates. In the first we used the 2 '-fluoro-modified AD1661 duplex (Table 1) in the LNP-KC2 formulation, but this time, we tested reagents for the quantification of the sense strand (mod sense; Figure 6a). In the second experiment we tested the antisense strand, duplex and formulated AD6490 (Table 1) in LNP-C12-200 formulation (Figure 6b). Both experiments demonstrated a linear range over 4 logs and the ability to quantify siRNA between the ranges of $0.7 \mu \mathrm{g} / \mathrm{g}$ to $70 \mathrm{pg} / \mathrm{g}$ of liver tissue.

\section{Quantification of siRNA and target expression in rat liver}

To quantify siRNAs in vivo, an intravenous dosing study was performed targeting FVII in rat liver. Single doses $(0.0625,0.125$, or $0.25 \mathrm{mg} / \mathrm{kg})$ of LNP-KC2-formulated modified duplex AD1661 were delivered to rats and 


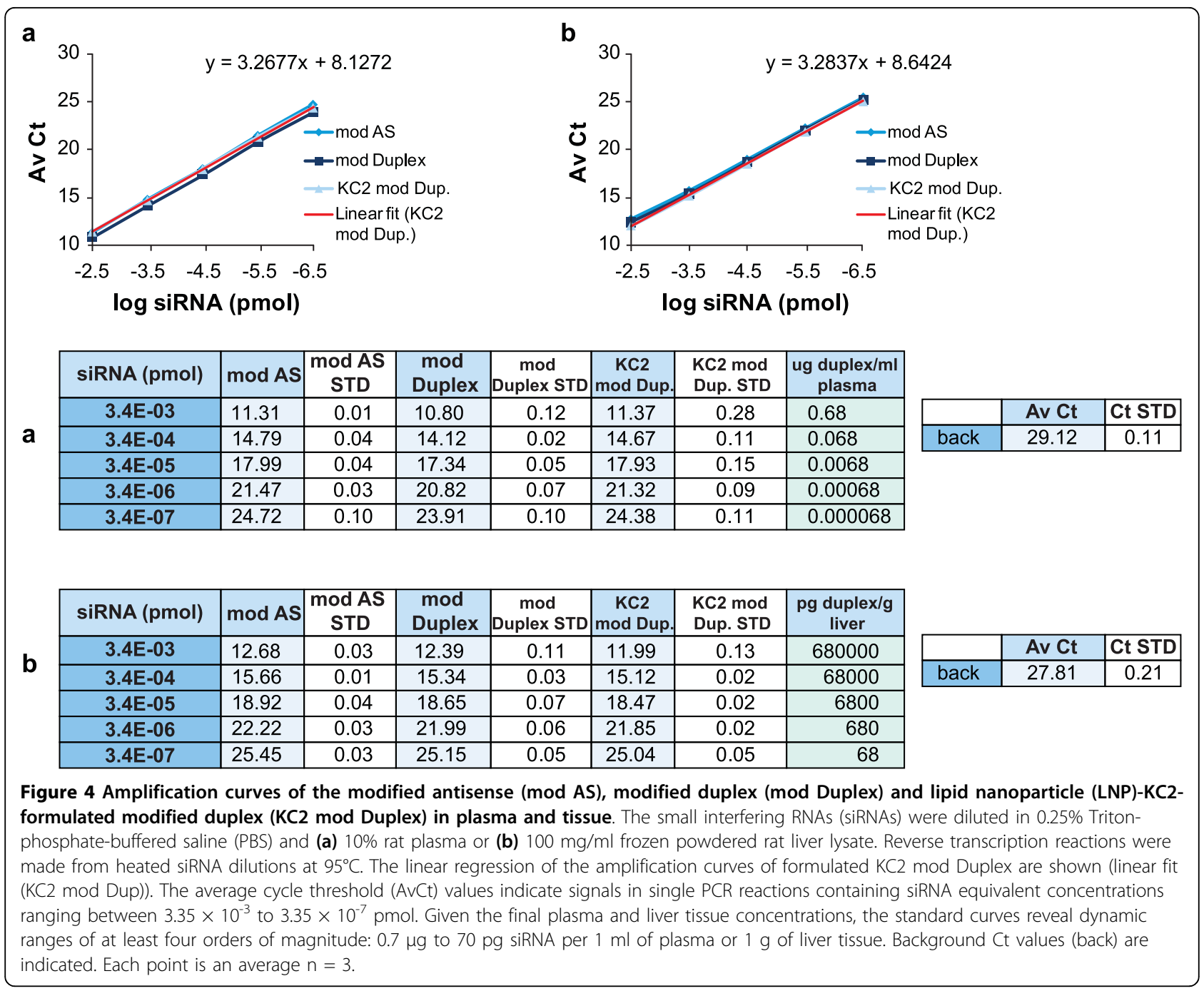

both FVII RNA levels and siRNA concentrations were monitored over 20 days (Figure 7a). The drug elimination curves showed dose proportional clearance with average residual siRNA of $0.01 \%$ at day 10 in rat liver (Figure 7b). At all doses tested, siRNAs could be detected up to day 10 post dosing. A lower limit of detection (LLOD) of $25.8 \pm 4.6 \mathrm{pg} / \mathrm{g}$ was calculated from the phosphate-buffered saline (PBS)-treated rats.

FVII transcript levels measured in liver by qRT-PCR assay decreased by as much as $80 \%$ at 1 day post siRNA administration (Figure 7c) and were tightly correlated with siRNA levels across the three doses and at all time points tested (see Figure $7 d$; linear regression significant at $P<0.01$ ). Independent of the dose delivered, only $1.6 \pm 0.8 \mathrm{ng}$ of siRNA per $1 \mathrm{~g}$ of liver was needed to achieve the $\mathrm{ED}_{50}$ of FVII gene silencing (Figure $7 \mathrm{~d}$ ). Assuming $1.5 \times 10^{8}$ cells/g liver tissue [15], the amount of siRNA at the $\mathrm{ED}_{50}$ is equivalent to approximately 500 siRNA molecules/liver cell. The linear regression also indicates that to achieve $80 \%$ target depletion, approximately $15 \pm 8 \mathrm{ng}$ siRNA/g liver is required. Such concentrations were attained only on day 1 in the rats that were injected with 0.125 and $0.25 \mathrm{mg} / \mathrm{kg}$ of AD1661 (Figure 7c).

Prediction of specificity: recognition of siRNA metabolites The annealing of single strand RNAs to specific stemloop RT oligonucleotides is a prerequisite for quantitative RT, which generates the first strand cDNA. Efficient synthesis of the second cDNA strand depends on the annealing of the newly synthesised cDNA to a specific forward primer. In this work, we designed stem-loop oligonucleotides that share 6 nucleotides of complementarity with the $3^{\prime}$ end of the siRNA and forward primers with 18 nucleotides of complementarity with the $5^{\prime}$ end of the first strand cDNA (see Methods). In addition to efficiently detecting full-length product, this primer design would be expected to allow detection of 


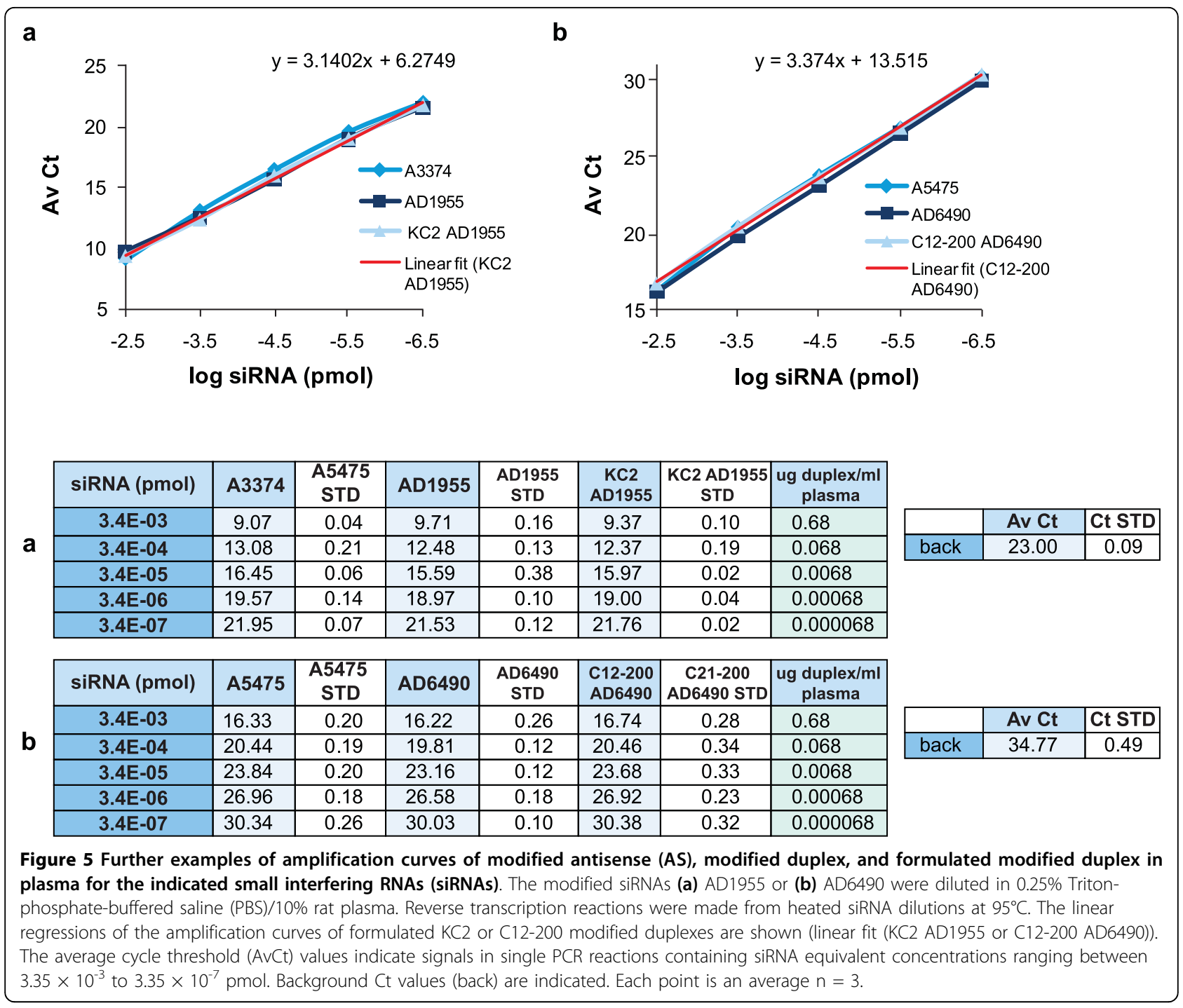

truncated siRNAs such as those generated though metabolism in vivo. To evaluate the degree of metabolite detection by this assay, a set of 19 truncated modified antisense strands were synthesised; 13 of these oligonucleotides contained $5^{\prime}$ truncations and 6 contained $3^{\prime}$ truncations (Table 2). We then tested the ability of the HIT qRT-PCR assay to discriminate among these truncated oligonucleotides. As expected based on the design features described above, we observed asymmetry between the ability to detect $5^{\prime}$ and $3^{\prime}$ truncated oligonucleotides (Figure 8). While there was a gradual loss in detection of $5^{\prime}$ end truncations (Figure 8a), an abrupt loss of detection was observed with the elimination of only three bases on the $3^{\prime}$ end of the antisense oligonucleotide (Figure $8 \mathrm{~b}$ ). Truncation of 6 nucleotides at the 5 ' end reduced the detection sensitivity by 10 -fold compared to the full-length antisense strand and the truncation of 9 nucleotides reduced that signal by 100-fold (Figure 8a).

\section{Discussion}

The HIT qRT-PCR assay (Figure 9) represents a significant improvement over the previously published stemloop qRT-PCR method [8] as it allows a reliable and sensitive quantification of the sense or antisense strand of formulated and chemically modified siRNAs from in vivo samples. The improvements include protocols for processing tissue samples without the need for RNA purification. The resulting assay has a dynamic range exceeding four orders of magnitude and a sensitivity that surpasses other published methods $[4,7,9]$. For plasma and tissue detection, samples are directly diluted in $0.25 \%$ Triton and heated to $95^{\circ} \mathrm{C}$ to efficiently release the encapsulated siRNA from the LNP. To achieve 

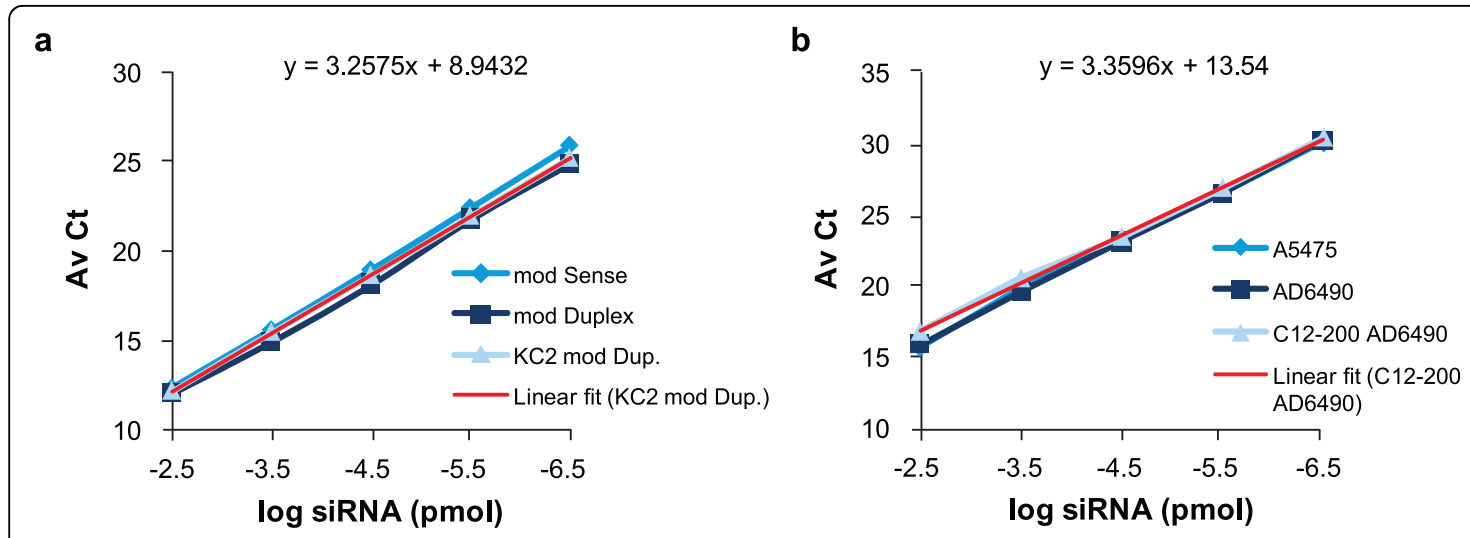

\begin{tabular}{|c|c|c|c|c|c|c|c|}
\hline siRNA (pmol) & $\begin{array}{c}\text { mod } \\
\text { sense }\end{array}$ & \begin{tabular}{|c|} 
mod \\
sense STD
\end{tabular} & $\begin{array}{c}\text { mod } \\
\text { Duplex }\end{array}$ & $\begin{array}{c}\text { mod } \\
\text { Duplex STD }\end{array}$ & $\begin{array}{c}\text { KC2 } \\
\bmod \text { Dup }\end{array}$ & $\begin{array}{l}\text { KC2 mod } \\
\text { Dup. STD }\end{array}$ & $\begin{array}{c}p g \text { duplex/g } \\
\text { liver }\end{array}$ \\
\hline 3.4E-03 & 12.39 & 0.29 & 12.08 & 0.12 & 12.19 & 0.49 & 680000 \\
\hline 3.4E-04 & 15.64 & 0.10 & 14.96 & 0.23 & 15.49 & 0.41 & 68000 \\
\hline $3.4 \mathrm{E}-05$ & 18.97 & 0.17 & 18.15 & 0.26 & 18.67 & 0.50 & 6800 \\
\hline $3.4 \mathrm{E}-06$ & 22.43 & 0.28 & 21.81 & 0.13 & 21.99 & 0.35 & 680 \\
\hline $3.4 \mathrm{E}-07$ & 25.90 & 0.29 & 24.92 & 0.06 & 25.23 & 0.26 & 68 \\
\hline
\end{tabular}

\begin{tabular}{|c|c|c|}
\hline & Av Ct & Ct STD \\
\hline back & 31.05 & 0.54 \\
\hline
\end{tabular}

\begin{tabular}{|c|l|c|c|c|c|c|c|}
\hline siRNA (pmol) & A5475 & $\begin{array}{c}\text { STD } \\
\text { A5475 }\end{array}$ & AD6490 & $\begin{array}{c}\text { STD } \\
\text { AD6490 }\end{array}$ & $\begin{array}{c}\text { MC20 } \\
\text { AD6490 }\end{array}$ & $\begin{array}{c}\text { STD MC20 } \\
\text { AD6490 }\end{array}$ & $\begin{array}{c}\text { pg duplex/g } \\
\text { liver }\end{array}$ \\
\hline b & 15.66 & 0.24 & 15.90 & 0.15 & 16.79 & 0.13 & 680000 \\
\hline $3.4 E-03$ & 19.87 & 0.23 & 19.59 & 0.07 & 20.54 & 0.20 & 68000 \\
\hline $3.4 E-05$ & 23.36 & 0.14 & 23.16 & 0.06 & 23.46 & 0.54 & 6800 \\
\hline $3.4 E-06$ & 26.55 & 0.29 & 26.51 & 0.30 & 26.89 & 0.41 & 680 \\
\hline $3.4 E-07$ & 30.10 & 0.46 & 30.24 & 0.20 & 30.42 & 0.38 & 68 \\
\hline
\end{tabular}

\begin{tabular}{|c|c|c|}
\hline & Av Ct & Ct STD \\
\hline back & 35.57 & 0.39 \\
\hline
\end{tabular}

Figure 6 Further examples of amplification curves of modified antisense (AS), modified duplex, and formulated modified duplex in liver tissue for the indicated small interfering RNAs (siRNAs). The modified siRNAs (a) AD1661 or (b) AD6490 were diluted in 0.25\% Tritonphosphate-buffered saline (PBS) in rat liver at final concentration of $100 \mathrm{mg} / \mathrm{ml}$. Reverse transcription reactions were made from heated siRNA dilutions at $95^{\circ} \mathrm{C}$. For $\mathrm{AD} 1661$ the assay analysed the sense strand. In this experiment the modified sense strand A4723 serves as the single strand control. The linear regressions of the amplification curves of formulated KC2 or C12-200 modified duplexes are shown (linear fit (KC2 AD1661 or C12-200 AD6490)). The average cycle threshold (AvCt) values indicate signals in single PCR reactions containing siRNA equivalent concentrations ranging between $3.35 \times 10^{-3}$ to $3.35 \times 10^{-7}$ pmol. Background Ct values (back) are indicated. Each point is an average $\mathrm{n}=3$.

efficient amplification, plasma and tissue samples are then centrifuged to remove debris, and reheated to $95^{\circ} \mathrm{C}$ to ensure efficient strand separation for the RT reaction. Comparable quantitation of antisense strands alone versus modified and formulated duplexes confirms that complete duplex denaturation occurs.

The HIT siRNA quantification method extends the work of Chen et al., who developed the original stemloop qRT-PCR method for the quantification of miRNAs [8]. They demonstrated high assay sensitivity and showed its broad utility by measuring the levels of 10 different miRNAs from tissue culture cells, using various sample preparation techniques. Specifically, they observed that quantification from a PBS-boiled tissue culture suspension was as efficient as that from purified RNA, thus eliminating the RNA purification step in their protocol. While the direct boiling/cooling method described by Chen was simple, it was clear that additional steps were needed to make this protocol suitable for the quantification of chemically modified and formulated siRNAs from animal tissue. Importantly, efficient strand separation turned out to be critical for accurate quantification of siRNAs by qRT-PCR. Strand reannealing occurs rapidly in cooled siRNA lysates. As a result, the direct application of heat-denatured siRNAs into the $\mathrm{RT}$ reaction was required when measuring high concentrations of high Tm duplexes such as AD1661. In addition, effective siRNA quantification required complete release of the siRNA from the liposomal formulation, a challenge not relevant to endogenous miRNA detection assays. To accomplish this, $0.25 \%$ Triton at $95^{\circ} \mathrm{C}$ was added, as heating in PBS alone was not sufficient to fully liberate the duplex.

The rate of duplex reannealing is directly correlated with duplex concentration and inversely correlated with increased temperature. The highest siRNA concentration in an RT reaction used in our experiments was $17 \mathrm{nmol}$, from which $33.5 \mathrm{fmol}$ were analysed in one 
a

Day 0, injection of $0.0625,0.125$ or $0.25 \mathrm{mg} / \mathrm{kg}$

Formulated siRNA (LNP-KC2-AD1661)

$\downarrow$

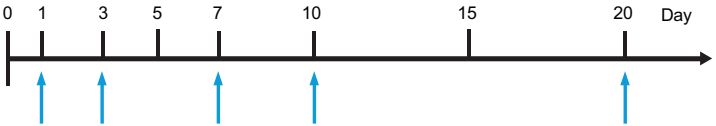

5 time points of liver collection, 3 rats per group
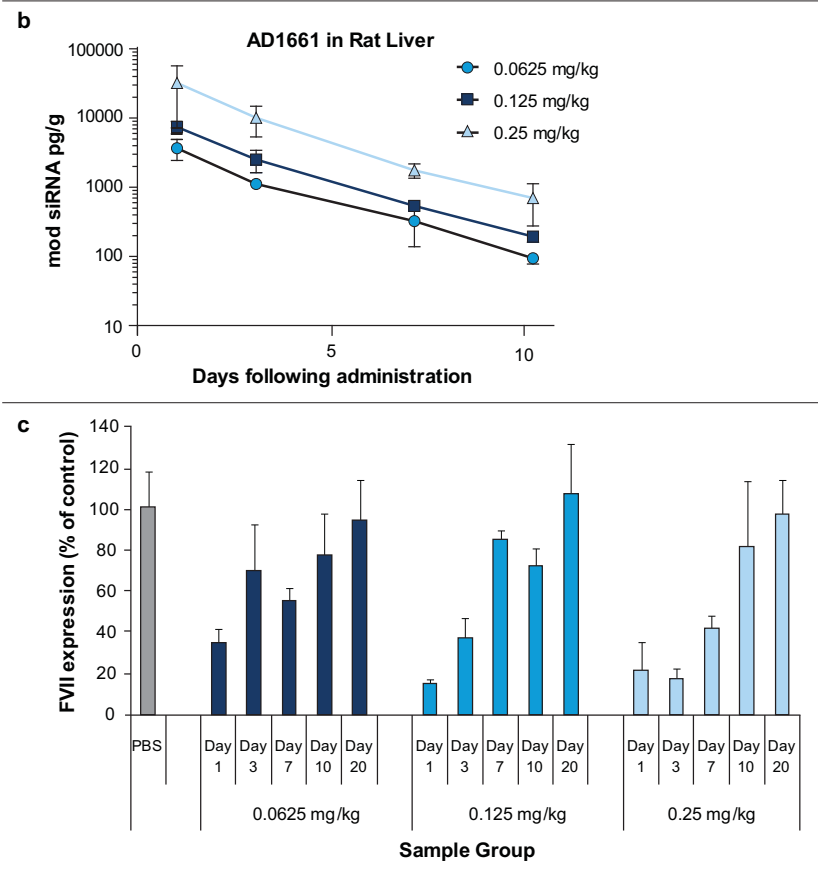

d

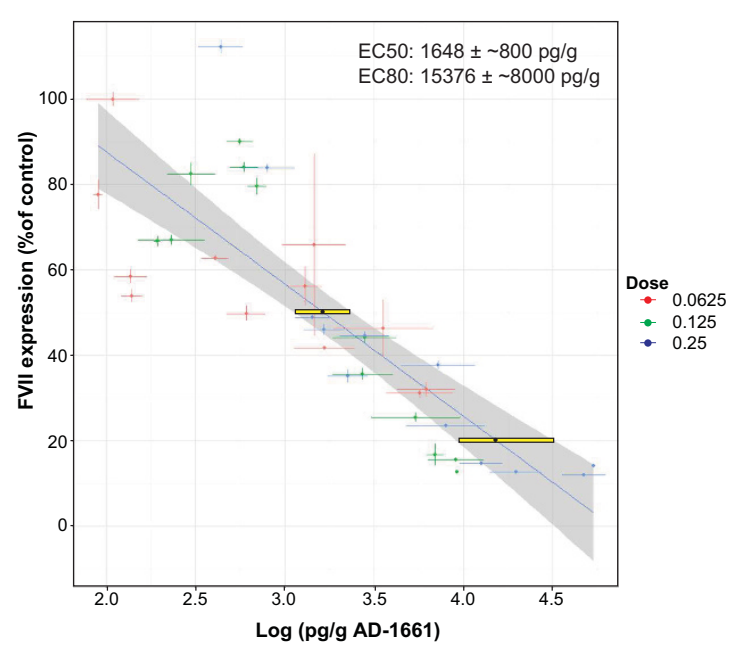

Figure 7 Correlation between in vivo delivered small interfering RNA (siRNA) and target knockdown in rat liver. (a) Experimental setup. Rats were tail-vein injected with phosphate-buffered saline (PBS), $0.0625,0.125$ and $0.25 \mathrm{mg} / \mathrm{kg}$ chemically modified and formulated siRNA in lipid nanoparticle (LNP)-KC2 (LNP-KC2-AD1661) on day 0. At 1, 3, 7, 10 and 20 days after injection, frozen powdered liver from three rats from each group was analysed for siRNA concentration and for target (factor VII (FVII)) expression. (b) Quantification of modified siRNA in rat liver. Average of three rats, measured twice independently, with day 20 levels below lower limit detection and therefore not shown (lowest limit of detection (PBS) = $25.8 \pm 4.6$ pg/g). (c) Gene target knockdown in rat liver. The average of FVII RNA expression in three rats, relative to FVII expression in PBS injected rats. (d) Correlation between siRNA drug levels and FVII RNA levels over time in rat livers. Symbols represent means \pm 1 standard error (SE) for individual rats. Blue line, linear regression; grey shading indicates $95 \%$ confidence interval. Yellow rectangles indicate $50 \%$ effective dose (EC50) and EC80 estimates. 
Table 2 Set of $5^{\prime}$ and $3^{\prime}$ truncations of the modified antisense A4724

\begin{tabular}{|c|c|}
\hline Truncation name & Sequence $5^{\prime}-3^{\prime}$ \\
\hline Full-length AS & GUfAAGACfUfUfGAGAUfGAUfCfCfdTsdT \\
\hline $5^{\prime} \mathrm{N}-1$ & UfAAGACfUfUfGAGAUfGAUfCfCfdTsdT \\
\hline $5^{\prime} \mathrm{N}-2$ & AAGACfUfUfGAGAUfGAUfCfCfdTsdT \\
\hline $5^{\prime} \mathrm{N}-3$ & AGACfUfUfGAGAUfGAUfCfCfdTsdT \\
\hline $5^{\prime} N-4$ & GACfUfUfGAGAUfGAUfCfCfdTsdT \\
\hline $5^{\prime} N-5$ & ACfUfUfGAGAUfGAUfCfCfdTsdT \\
\hline $5^{\prime} \mathrm{N}-6$ & CfUfUfGAGAUfGAUfCfCfdTsdT \\
\hline $5^{\prime} \mathrm{N}-7$ & UfUfGAGAUfGAUfCfCfdTsdT \\
\hline $5^{\prime} \mathrm{N}-8$ & UfGAGAUfGAUfCfCfdTsdT \\
\hline $5^{\prime} N-9$ & GAGAUfGAUfCfCfdTsdT \\
\hline $5^{\prime} \mathrm{N}-10$ & AGAUfGAUfCfCfdTsdT \\
\hline $5^{\prime} \mathrm{N}-11$ & GAUfGAUfCfCfdTsdT \\
\hline $5^{\prime} \mathrm{N}-12$ & AUfGAUfCfCfdTsdT \\
\hline $5^{\prime} \mathrm{N}-13$ & UfGAUfCfCfdTsdT \\
\hline $3^{\prime} \mathrm{N}-1$ & GUfAAGACfUfUfGAGAUfGAUfCfCfdT \\
\hline $3^{\prime} \mathrm{N}-2$ & GUfAAGACfUfUfGAGAUfGAUfCfCf \\
\hline $3^{\prime} \mathrm{N}-3$ & GUfAAGACfUfUfGAGAUfGAUfCf \\
\hline $3^{\prime} N-4$ & GUfAAGACfUfUfGAGAUfGAUf \\
\hline $3^{\prime} N-5$ & GUfAAGACfUfUfGAGAUfGA \\
\hline $3^{\prime} N-6$ & GUfAAGACfUfUfGAGAUfG \\
\hline
\end{tabular}

The full-length antisense (AS) strand sequence is indicated, along with the sequences of $5^{\prime}\left(5^{\prime} \mathrm{N}-1\right.$ to $\left.5^{\prime} \mathrm{N}-13\right)$ and $3^{\prime}\left(3^{\prime} \mathrm{N}-1\right.$ to $\left.3^{\prime} \mathrm{N}-6\right)$ truncated oligonucleotides. Chemical modifications are shown as follows: $2^{\prime}$-fluoromodified nucleotides are shown by ' $f$ ' following the modified nucleotide and phosphorothioate linkages are shown by ' $s$ '. All sequences are written in the 5'-3' direction.

qRT-PCR reaction. At that concentration, reannealing of duplexes occurred rapidly and amplification was not fully efficient, as evidenced by the non-linearity of the curves at this input dose (see the -1.5 points in Figures $1 \mathrm{~d}$ and 3a). Based on this observation, the upper limit of quantification for our standard curves was defined as 3.4 fmol per qRT-PCR reaction. This translated to approximately $0.7 \mu \mathrm{g}$ duplex/ml plasma and $0.7 \mu \mathrm{g}$ duplex/g of liver tissue (Figure 4). The average lowest limit of quantification was 0.34 attmol of siRNA, translated to approximately $70 \mathrm{pg}$ duplex $/ \mathrm{ml}$ plasma and $70 \mathrm{pg}$ duplex/g of liver tissue, yielding signals that are 4-fold to 10-fold above background signal (a difference of 2-3 Av Ct units).

Having developed an assay for the quantification of formulated and chemically modified siRNA in liver tissue or plasma, the next challenge was to use this assay for the quantification of such siRNAs delivered to rats by intravenous dosing. The goal was to quantify the siRNA antisense strand from siRNA duplex that targets FVII mRNA in rat liver. The antisense strand was selected as it represents the functional targeting strand, but the assay is equally amenable to sense strand

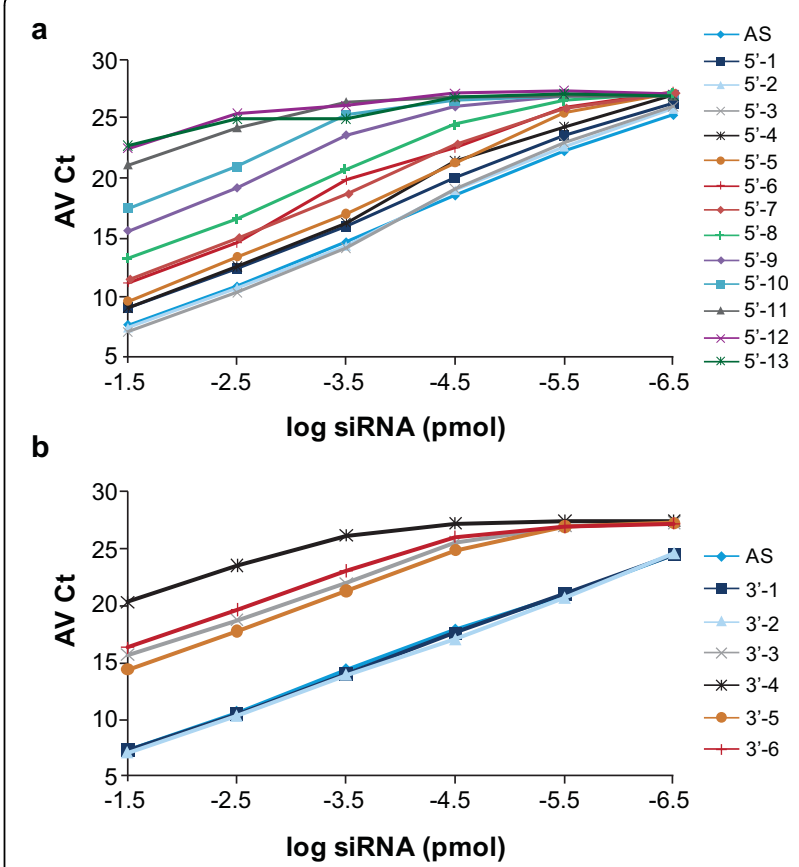

Figure 8 The detection of full-length, $5^{\prime}$ and $3^{\prime}$ truncated antisense oligonucleotides. (a) The $5^{\prime}$-truncated oligonucleotides $\left(5^{\prime} \mathrm{N}-1\right.$ to $5^{\prime} \mathrm{N}-13$ ) and (b) $3^{\prime}$-truncated oligonucleotides ( $3^{\prime} \mathrm{N}-1$ to $3^{\prime}$ $\mathrm{N}-6$ ) were tested in 10-fold serial dilutions by the heating-in-Triton quantitative reverse transcription PCR (HIT qRT-PCR) method. The sequences of these oligonucleotides and their nomenclature are detailed in Table 2. The average cycle threshold (AvCt) values indicate signals in single PCR reactions containing small interfering RNA (siRNA)-equivalent concentrations ranging between $3.35 \times 10^{-2}$ to $3.35 \times 10^{-7}$ pmol. Each point is an average $n=3$.

detection (Figure 6a). In this in vivo experiment, 0.0625 , 0.125 and $0.25 \mathrm{mg} / \mathrm{kg}$ of LNP-KC2-formulated AD1661 were delivered as single doses, and samples were quantified for both target mRNA and siRNA levels at 1, 3, 7, 10 , or 20 days post dosing. A linear correlation between the amounts of siRNA delivered and target knockdown was observed in the rat livers (Figure 7). This correlation indicated that independent of the dose administered, approximately $1.6 \pm 0.8 \mathrm{ng} / \mathrm{g}$ of modified AD1661 siRNA resulted in an approximately $50 \%$ reduction of FVII mRNA $\left(\mathrm{ED}_{50}=\right.$ approximately $\left.1.6 \pm 0.8 \mathrm{ng} / \mathrm{g}\right)$. This translates to an average of 500 siRNA molecules/cell in rat liver.

To confirm that extraction of siRNA using the HIT qRT-PCR protocol is efficient, we repeated the assay on a subset of the above rat liver tissue samples using a phenol chloroform extraction protocol. The Ct values measured from these two assay protocols were almost identical suggesting that the HIT qRT-PCR assay protocol efficiently liberates siRNAs for easy detection (data not shown). This experiment not only confirmed the quantification results by another method, but also 


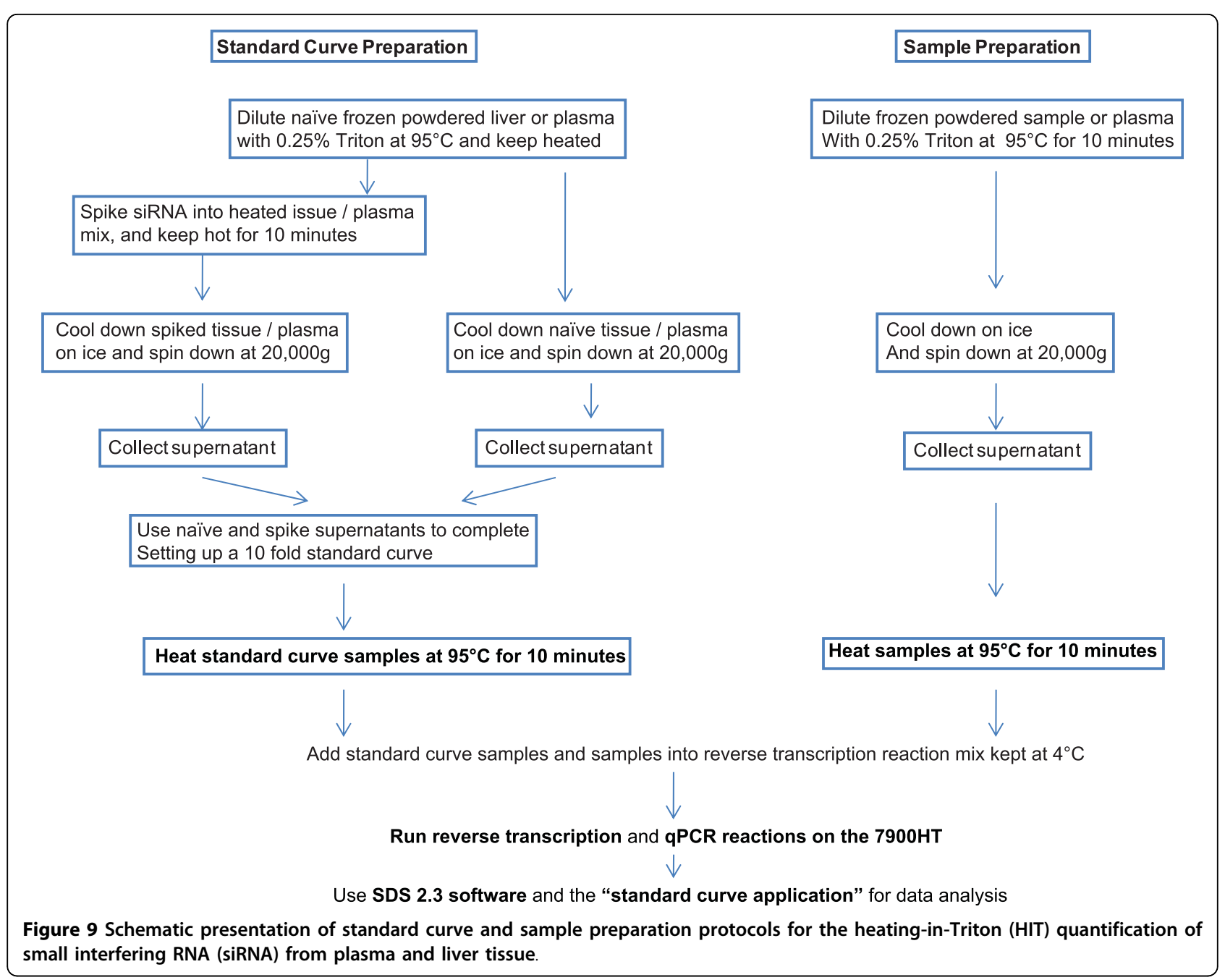

assured us that our extraction method results in efficient release of protein bound siRNA, such as might be bound to the Argonaute 2 (Ago2) protein.

By analysing sets of truncated antisense molecules we aimed to predict the type of siRNA metabolites that one may detect when using the HIT qRT-PCR method. As expected, the assay is more sensitive to $3^{\prime}$ end truncations than to $5^{\prime}$ end truncations (Figure 8). We observed that siRNA metabolites that include strand truncations of up to five nucleotides at their $5^{\prime}$ end and up to two nucleotides on their $3^{\prime}$ end are detected by the HIT qRT-PCR method with reasonable efficiency. Future assay development, including modifications of primer length, will further improve HIT qRT-PCR's ability to specifically measure full-length and siRNA metabolites.

\section{Conclusions}

In summary, we developed a reliable, reproducible and highly sensitive method of quantitating siRNAs delivered in vivo. As more siRNA therapeutic programmes are initiated and move into preclinical and clinical stages, accurate quantification of siRNA levels across various tissues will become crucially important. This method allows the correlation of pharmacodynamic with precise pharmacokinetic measures, using a sensitive and easy to perform assay that will contribute to the successful development of siRNA therapeutics.

\section{Methods}

Oligonucleotides (Integrated DNA Technologies, IA, USA) and TaqMan probes (Applied Biosystems of Life Technologies, CA, USA) (Table 3) were designed according to Chen et al. [8].

siRNAs were formulated either in LNP-KC2 [5], or in LNP- C12-200 [14].

\section{Quantification of siRNA in liver tissue or plasma in}

$0.25 \%$ Triton: the HIT qRT-PCR protocol (Figure 9)

Following plasma collection and necropsy, plasma and liver samples were kept frozen and liver tissue ground 
Table 3 Oligonucleotides and TaqMan probes for the stem-loop real time PCR assays

\begin{tabular}{lll}
\hline Assay & Primer/probe & Sequence \\
\hline AD1596 & Stem-loop RT & GTCGTATCCAGTGCAGGGTCCGAGGTATTCGCACTGGATACGACAAGGAT \\
& Forward primer & GCCCGCGTAAGACTTGAGATGATC \\
& Reverse primer & GTGCAGGGTCCGAGGT \\
& TaqMan probe & (6-FAM) CTGGATACGACAAGGAT (MGB) \\
AD6490 & Stem-loop RT & GTCGTATCCAGTGCAGGGTCCGAGGTATTCGCACTGGATACGACAGGGAA \\
& Forward primer & CCCGCTGGATCAAATATAAGATT \\
& Reverse primer & GTGCAGGGTCCGAGGT \\
& TaqMan probe & (6-FAM) CTGGATACGACAGGGAA (MGB) \\
AD1955 & Stem-loop RT & \\
& Forward primer & TCGTATCCAGTGCAGGGTCCGAGGTATTCGCACTGGATACGACAACTTA \\
& TaqMan probe & GTGCAGGGTCCGAGGT \\
& (6-FAM) CTGGATACGACAACTTA (MGB) \\
AD1661 & \\
(sense) & Gtem-loop RT & \\
& Forward primer & Reverse primer \\
& TaqMan probe & GCCCGCGGATCATCTCAAGTCTTA \\
\hline All & GTGCAGGGTCCGAGGT \\
& (6-FAM) CTGGATACGACAAGTAA (MGB) \\
\hline
\end{tabular}

All assays designed to detect the antisense strands of the indicated duplexes, except for the indicated assay designed for sense strand detection. All sequences are written in the $5^{\prime}-3^{\prime}$ direction.

6-FAM = 6-carboxyfluorescein; MGB = minor groove binder; RT = reverse transcription.

for 2 minutes $(\mathrm{min})$ at 250 strokes/min using a Geno Grinder (SPEXP SamplePrep, NJ, USA) to achieve a light homogeneous powder.

\section{Preparation of standard curves}

Duplex, antisense and formulated siRNAs $(20 \mu \mathrm{M})$ were used for the preparation of serial 10-fold dilutions into $95^{\circ} \mathrm{C}$ boiled tissue $(100 \mathrm{mg} / \mathrm{ml})$ or plasma (1:10 diluted) in $0.25 \%$ Triton X-100 in PBS, as detailed below.

For tissue, $500 \mu \mathrm{l}$ of $0.25 \%$ Triton $\mathrm{X}-100$ at $95^{\circ} \mathrm{C}$ was added directly into $50 \mathrm{mg}$ of naïve (PBS-treated animal) frozen powdered tissue. The lysate was vortexed and put back into the $95^{\circ} \mathrm{C}$ hot block. Then, $12.5 \mu \mathrm{l}$ of $20 \mu \mathrm{M}$ siRNA was added into the hot lysate, which was then vortexed again and put back into the hot block for a total incubation time of $10 \mathrm{~min}$. This procedure was performed once for formulated duplex, naked duplex and for antisense or sense strands. Additional tubes with naïve tissue lysates in $0.25 \%$ Triton $\mathrm{X}-100$ were heated at $95^{\circ} \mathrm{C}$. These were used for the preparation of the standard curve points. Following $10 \mathrm{~min}$ at $95^{\circ} \mathrm{C}$, all lysates were cooled on ice for $10 \mathrm{~min}$.

For plasma, plasma from naïve animals (PBS treated) was diluted $1: 10$ in $0.25 \%$ Triton $\mathrm{X}-100$, and $500 \mu \mathrm{l}$ taken into an Eppendorf tube and heated in a $95^{\circ} \mathrm{C}$ hot block. Then, $12.5 \mu \mathrm{l}$ of $20 \mu \mathrm{M}$ siRNA was added into the hot lysate, which was then vortexed again and put back into the hot block for a total incubation time of $10 \mathrm{~min}$. This procedure was performed once for formulated duplex, naked duplex and for antisense or sense strands. Additional tubes with naïve plasma lysates in $0.25 \%$ Triton X-100 were heated at $95^{\circ} \mathrm{C}$. These were used for the preparation of the standard curve points. Following $10 \mathrm{~min}$ at $95^{\circ} \mathrm{C}$, all lysates were cooled on ice for $10 \mathrm{~min}$.

Cooled tissue and plasma lysate tubes were centrifuged at $20,000 \mathrm{~g}$ for $20 \mathrm{~min}$ at $4^{\circ} \mathrm{C}$ and supernatants placed into clean Eppendorf tubes and kept on ice.

The naïve and siRNA-spiked (500 nmol), heated and cleared tissue or plasma lysates were used to prepare 10 -fold serial dilution points $(50 \mathrm{nmol}$ to $50 \mathrm{fmol}$ ) for the standard curves.

\section{Preparation of liver and plasma samples for the quantification of siRNA}

For tissue, $500 \mu \mathrm{l}$ of $0.25 \%$ Triton $\mathrm{X}-100$ at $95^{\circ} \mathrm{C}$ was added directly into each $50 \mathrm{mg}$ frozen powdered tissue sample. Lysates were vortexed and put back into the $95^{\circ} \mathrm{C}$ hot block for a total incubation time of $10 \mathrm{~min}$. Lysates were vortexed twice more during this incubation. Following $10 \mathrm{~min}$ at $95^{\circ} \mathrm{C}$, all lysates were cooled on ice for $10 \mathrm{~min}$.

For plasma, plasma samples were diluted $1: 10$ in $0.25 \%$ Triton X-100. Then, $500 \mu \mathrm{l}$ from each diluted plasma 
sample was heated at $95^{\circ} \mathrm{C}$ for a total incubation time of $10 \mathrm{~min}$ and vortexed twice during this incubation. Following $10 \mathrm{~min}$ at $95^{\circ} \mathrm{C}$, all lysates were cooled on ice for $10 \mathrm{~min}$.

All tissue and plasma lysates were centrifuged at $20,000 \mathrm{~g}$ for $20 \mathrm{~min}$ at $4^{\circ} \mathrm{C}$ and supernatants taken into clean Eppendorf tubes and kept on ice.

\section{Reverse transcription reactions}

Reverse transcription reactions were performed using a TaqMan MicroRNA Reverse Transcription kit 200 (Applied Biosystems of Life Technologies, cat \# 4366596).

We recommend using two adjacent PCR machines for the procedure. One PCR machine for heating the 'boiling plate' and the second for the 'RT plate', as detailed below.

A total of $50 \mu \mathrm{l}$ from each standard curve point (single strand, duplex and formulated duplex), one naïve (for background) and sample lysates were aliquoted into one PCR plate ('boiling plate') and heated at $95^{\circ} \mathrm{C}$ for $10 \mathrm{~min}$ on one PCR machine. Then, $10 \mu \mathrm{l}$ of RT reaction mix (100 mmol deoxyribonucleotide triphosphates, $250 \mathrm{nmol}$ stem and loop oligonucleotides, $20 \mathrm{U} / \mu \mathrm{l}$ RNase inhibitor, $1 \times$ RT buffer, $50 \mathrm{U} / \mu \mathrm{l}$ MultiScribe Reverse Transcriptase) was aliquoted into each well of the 'RT plate', which was placed on the second adjacent PCR machine and kept at $4{ }^{\circ} \mathrm{C}$. Following $10 \mathrm{~min}$ of heating, the cover from the 'boiling plate' was removed and, while the plate was kept on the heating block, $5 \mu \mathrm{l}$ from each hot sample was directly added into the $\mathrm{RT}$ reaction mix (at $4^{\circ} \mathrm{C}$ ) on the 'RT plate' and the program was switched onto the RT program $\left(30 \mathrm{~min}, 16^{\circ} \mathrm{C}, 30 \mathrm{~min}, 42^{\circ} \mathrm{C}\right.$, 5 min, $85^{\circ} \mathrm{C}$ ).

\section{PCR amplification}

A total of $2 \mu \mathrm{l}$ of cDNA from the previous step was added into the PCR amplification reaction mix $(0.2 \mu \mathrm{M}$ TaqMan probe, $1.5 \mu \mathrm{M}$ forward primer, $0.7 \mu \mathrm{M}$ reverse primer, TaqMan $2 \times$ Universal PCR Master Mix, No AmpErase UNG; Applied Biosystems of Life Technologies, cat \# 4366596). The ABI 7900HT Sequence Detection System and the 'Standard Curve' application SDS 2.3 (Applied Biosystems of Life Technologies) were used to run the PCR reaction.

\section{Quantification of Gene knockdown in rat liver}

An RNeasy mini kit (Qiagen Inc. Valencia, CA, USA, cat \# 74106) was used to purify total RNA from frozen powdered rat liver. A High Capacity cDNA Reverse Transcription Kit (Applied Biosystems of Life Technologies, cat \# 4368814) was used for RT. TaqMan Assays Rat FVII (cat \# Rn00596104_m1) and TaqMan Assay Rat GAPDH kit (cat \# 4352338E) together with TaqMan
Universal PCR Master Mix No AmpErase UNG (cat \# 4324020, all from Applied Biosystems of Life Technologies) were used for the amplification of rat FVII and GAPDH transcripts.

\section{Acknowledgements}

We thank Klaus Charisse for stimulating discussions. We thank Martin Maier, David Bumcrot, Tatiana Novobrantseva, Stuart Milstein, Amy White, Jamie Wong, Hila Epstein-Barash and the RLD group for helpful comments and discussions. We thank Ken Kulmatycki for participating in planning the in vivo experiment. We thank Lauren Lesser for graphic support.

\section{Authors' contributions}

YL conceived the study, designed and performed experiments, analysed results, and drafted the manuscript. NS and AC performed experiments and analysed results. XZ performed the animal experiments, BRB performed statistical analysis SK and KD designed and synthesised the truncated oligonucleotides, SS performed Tm measurements. MG performed initial experiments and analysed results. AA planned the in vivo experiment and with RH provided critical analysis of the in vivo data. RM provided critical review and discussion and manuscript revision. All authors read and approved the final manuscript.

\section{Competing interests}

The authors declare that they have no competing interests.

Received: 14 May 2010 Accepted: 23 August 2010

Published: 23 August 2010

\section{References}

1. de Fougerolles A, Vornlocher HP, Maraganore J, Lieberman J: Interfering with disease: a progress report on siRNA-based therapeutics. Nat Rev Drug Discov 2007, 6:443-453.

2. de Fougerolles AR: Delivery vehicles for small interfering RNA in vivo. Hum Gene Ther 2008, 19:125-132.

3. Novobrantseva Tl, Akinc A, Borodovsky A, de Fougerolles A: Delivering silence: advancements in developing siRNA therapeutics. Curr Opin Drug Discov Devel 2008, 11:217-224.

4. Jackson AL, Linsley PS: Recognizing and avoiding siRNA off-target effects for target identification and therapeutic application. Nat Rev Drug Discov 2010, 9:57-67.

5. Semple SC, Akinc A, Chen J, Sandhu AP, Mui BL, Cho CK, Sah DW Stebbing D, Crosley EJ, Yaworski E, Hafez IM, Dorkin JR, Qin J, Lam K, Rajeev KG, Wong KF, Jeffs LB, Nechev L, Eisenhardt ML, Jayaraman M, Kazem M, Maier MA, Srinivasulu M, Weinstein MJ, Chen Q, Alvarez R, Barros SA, De S, Klimuk SK, Borland T, Kosovrasti V, Cantley WL, Tam YK, Manoharan M, Ciufolini MA, Tracy MA, de Fougerolles A, MacLachlan I, Cullis PR, Madden TD, Hope MJ: Rational design of cationic lipids for siRNA delivery. Nat Biotechnol 2010, 28:172-176.

6. Tremblay GA, Oldfield PR: Bioanalysis of siRNA and oligonucleotide therapeutics in biological fluids and tissues. Bioanalysis 2009, 1:595-609.

7. Geary RS, Yu RZ, Watanabe T, Henry SP, Hardee GE, Chappell A, Matson J, Sasmor $H$, Cummins L, Levin AA: Pharmacokinetics of a tumor necrosis factor-alpha phosphorothioate 2'-O-(2-methoxyethyl) modified antisense oligonucleotide: comparison across species. Drug Metab Dispos 2003, 31:1419-1428.

8. Chen C, Ridzon DA, Broomer AJ, Zhou Z, Lee DH, Nguyen JT, Barbisin M, Xu NL, Mahuvakar VR, Andersen MR, Lao KQ, Livak KJ, Guegler KJ: Real-time quantification of microRNAs by stem-loop RT-PCR. Nucleic Acids Res 2005, 33:e179.

9. Stratford S, Stec S, Jadhav V, Seitzer J, Abrams M, Beverly M: Examination of real-time polymerase chain reaction methods for the detection and quantification of modified siRNA. Anal Biochem 2008, 379:96-104.

10. Cheng A, Li M, Liang Y, Wang Y, Wong L, Chen C, Vlassov AV, Magdaleno S: Stem-loop RT-PCR quantification of siRNAs in vitro and in vivo. Oligonucleotides 2009, 19:203-208.

11. Zimmermann TS, Lee AC, Akinc A, Bramlage B, Bumcrot D, Fedoruk MN, Harborth J, Heyes JA, Jeffs LB, John M, Judge AD, Lam K, McClintock K, Nechev LV, Palmer LR, Racie T, Röhl I, Seiffert S, Shanmugam S, Sood V, 
Soutschek J, Toudjarska I, Wheat AJ, Yaworski E, Zedalis W, Koteliansky V, Manoharan M, Vornlocher HP, MacLachlan I: RNAi-mediated gene silencing in non-human primates. Nature 2006, 441:111-114.

12. Akinc A, Goldberg M, Qin J, Dorkin JR, Gamba-Vitalo C, Maier M, Jayaprakash KN, Jayaraman M, Rajeev KG, Manoharan M, Koteliansky V, Röhl I, Leshchiner ES, Langer R, Anderson DG: Development of lipidoidsiRNA formulations for systemic delivery to the liver. Mol Ther 2009, 17:872-879.

13. Morrissey DV, Lockridge JA, Shaw L, Blanchard K, Jensen $K$, Breen W, Hartsough K, Machemer L, Radka S, Jadhav V, Vaish N, Zinnen S, Vargeese C, Bowman K, Shaffer CS, Jeffs LB, Judge A, MacLachlan I, Polisky B: Potent and persistent in vivo anti-HBV activity of chemically modified siRNAs. Nat Biotechnol 2005, 23:1002-1007.

14. Love KT, Mahon KP, Levins CG, Whitehead KA, Querbes W, Dorkin JR, Qin J, Cantley W, Qin LL, Racie T, Frank-Kamenetsky M, Yip KN, Alvarez R, Sah DW, de Fougerolles A, Fitzgerald K, Koteliansky V, Akinc A, Langer R, Anderson DG: Lipid-like materials for low-dose, in vivo gene silencing. Proc Natl Acad Sci USA 2010, 107:1864-1869.

15. Hendriks HF, Brouwer A, Knook DL: Isolation, purification, and characterization of liver cell types. Methods Enzymol 1990, 190:49-58.

doi:10.1186/1758-907X-1-16

Cite this article as: Landesman et al: In vivo quantification of

formulated and chemically modified small interfering RNA by heating-

in-Triton quantitative reverse transcription polymerase chain reaction

(HIT qRT-PCR). Silence 2010 1:16.

\section{Submit your next manuscript to BioMed Central} and take full advantage of:

- Convenient online submission

- Thorough peer review

- No space constraints or color figure charges

- Immediate publication on acceptance

- Inclusion in PubMed, CAS, Scopus and Google Scholar

- Research which is freely available for redistribution

Submit your manuscript at www.biomedcentral.com/submit 